\title{
On the radioactive marker technique for in-situ compaction measurements: a critical review
}

\author{
Massimiliano Ferronato, Matteo Frigo, Laura Gazzola, Pietro Teatini, and Claudia Zoccarato \\ Department ICEA, University of Padova, Padova, 35131, Italy \\ Correspondence: Massimiliano Ferronato (massimiliano.ferronato@unipd.it)
}

Published: 22 April 2020

\begin{abstract}
The regular monitoring of the relative position of a sequence of radioactive bullets shot through the well of a vertical borehole can provide in-situ measurements of deep rock compaction. Developed in the '70s, this technology has experienced a growing interest in the '90s, but in recent years, its use and relevance in land subsidence management above producing hydrocarbon reservoirs have been often debated. The present communication analyses the state of the art of the radioactive marker technique and provides a critical review on the role that these measurements might play in the future evolution of land subsidence monitoring and modelling.
\end{abstract}

\section{Introduction}

The Radioactive Marker Technique (RMT) was first introduced in the '70s to monitor the ongoing reservoir compaction during the exploitation of the Groningen gas field, the Netherlands (de Loos, 1973). After the initial promising applications, RMT experienced several technological improvements in the '90s and '00s and was used in a number of hydrocarbon fields worldwide, such as in the North Sea (Menghini, 1989), Gulf of Mexico (de Kock et al., 1998), and Northern Adriatic Sea (Ferronato et al., 2003). This technique consists in the regular monitoring of the relative position of a number of weakly radioactive bullets located at fixed intervals along a vertical, generally non-productive well (Fig. 1, Macini and Mesini, 2002). The most recent technological developments of the logging tool, currently managed by Schlumberger, allow for a nominal accuracy of the compaction measurements of $1 \mathrm{~mm}$ over a $10 \mathrm{~m}$ spacing.

In principle, the main objective of the RMT application in producing fields is twofold: (i) measuring the amount of reservoir compaction directly connected to hydrocarbon extraction activities, and (ii) estimating the mechanical properties of the reservoir rock to improve the quality of the subsidence modelling predictions. In recent years, however, the development of alternative cheaper techniques for such aims and the intrinsic RMT technological limitations, which can sometimes prevent from obtaining the expected outcome, have raised some concerns on the use of radioactive markers.
The present work provides a review of the status of the current RMT implementation and critically discusses its role and evolution in the next future. On one hand, the RMT competitiveness with respect to other promising techniques to monitor deep compaction, such as fiber optics, seems to be progressively decreasing as far as the temporal and spatial resolution is concerned.

On the other hand, the recent huge development of accurate subsidence monitoring strategies, e.g., InSAR and GPS, and numerical methods to derive the rock compressibility by inverse modelling, e.g, Data Assimilation algorithms, can partially reduce the need of deep compaction measurements. Finally, the experience acquired over almost 30 years of extensive RMT use in the Northern Adriatic basin suggests a progressive decay of the compaction measurement quality, with late data generally affected by a larger uncertainty and a significant noise.

\section{RMT implementation in the world}

The first RMT installation worldwide dates back to 1973 in the Groningen field, the Netherlands. At that time, the main issue was the accurate monitoring of land subsidence in highly vulnerable areas. The idea was to identify the deep reservoir compaction in order to derive the related vertical motion of the ground surface. It was soon realized, however, that the nominal accuracy of $1 \mathrm{~mm}$ over a $10 \mathrm{~m}$ compacting 


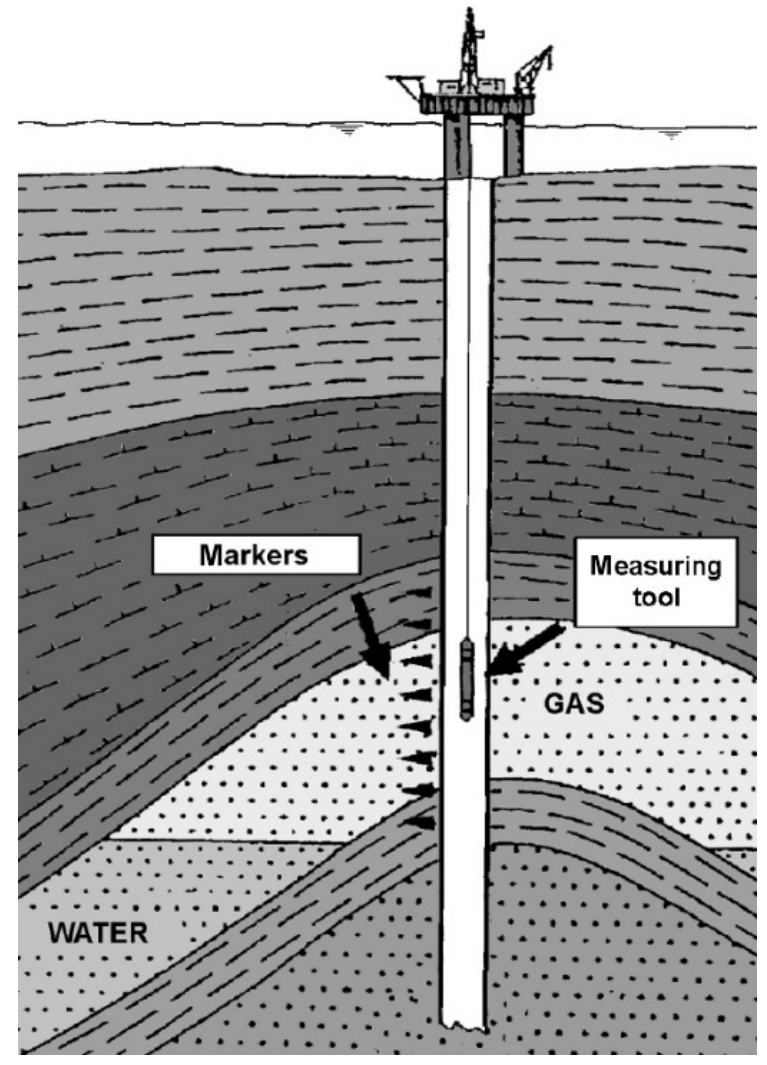

Figure 1. The Radioactive Marker Technique.

rock spacing was hard to obtain in practice. To cope with this difficulty, new algorithms for the radioactive signal analysis were introduced, leading to a more accurate marker detection (Mobach and Gussinklo, 1994). In the late '80s and early '90s, there was a growing interest in RMT, with applications in the Ekofisk and Valhall chalk fields, North Sea (Menghini, 1989), Champion oil field, offshore Brunei (Schmitt, 1996), and Gulf of Mexico (de Kock et al., 1998). The implementation in the chalk fields of the North Sea was particularly interesting. As it is well-known, the Ekofisk field was characterized by a very significant compaction, with important subsidence values affecting the offshore platform. Although "initial results from the time-lapse monitoring proved to be disappointing” (Menghini, 1989), most of the early technical issues were successfully addressed and the compaction monitoring is still active today.

In the '90s, RMT has been implemented in a number of gas fields located in the Northern Adriatic sedimentary basin, Italy (Macini and Mesini, 2002). By distinction with previous applications, the Northern Adriatic reservoirs, buried at a depth ranging from 1000 to $4500 \mathrm{~m}$, are characterized by a multi-pay structure of alternating sand and clay formations, with a thickness of the mineralized layers varying from dozens of meters to a few centimetres. In-situ compaction measurements led to compressibility estimates of the reser- voir rock that proved appreciably lower than those provided by lab tests on core samples (Cassiani and Zoccatelli, 2000), but generally more consistent with the measured land subsidence. Then, the RMT results were used to develop a hysteretic compressibility law for the sedimentary rock at the basin-scale (Baù et al., 2002), which was later supported by other experimental data (Hueckel et al., 2005; Ferronato et al., 2013). As new compaction data became available in time, however, the statistical dispersion of the compressibility estimates unexpectedly grew, with no benefits for the confidence interval of the compressibility law developed in the early '00s. Such an occurrence was related to a progressive decay in the quality of the detected RMT measurements and a number of studies were devoted to investigate this behaviour, e.g., Ferronato et al. (2004, 2007), Macini et al. (2006).

More recently, no other scientific publication on RMT is available. Compaction monitoring is currently ongoing only in Groningen, Ekofisk and Northern Adriatic. A recent technical report from NAM (Kole, 2015) analyses the condition of the marker-equipped boreholes in the Groningen field. The report notices that only 3 out of 8 wells are still used for monitoring purposes, but the quality of the collected data is progressively declining. The current accuracy does not exceed $5 \mathrm{~mm}$ over a $10 \mathrm{~m}$ spacing, observing that "for new fields, it is therefore unlikely that the GR marker technique will be applied in the future" (Kole, 2015). Another reason for the progressive lack of interest in RMT is its cost. For instance, the cost for drilling a $2000 \mathrm{~m}$ deep instrumented borehole in the Northern Adriatic presently amounts to about EUR $20 \mathrm{M}$, while a single FSMT survey costs approximately EUR $200 \mathrm{k}$.

\section{Technical issues}

The problems in the RMT use can be classified into two categories: (1) in-situ data collection; (2) data interpretation and use. Problems in class 1 mainly affect the quality of the recorded data, reducing the expected accuracy. Such difficulties can be usually addressed by improving the acquisition technology. By distinction, problems in class 2 basically concern the role that RMT measurements may play in modern computational geomechanics for land subsidence monitoring and prediction.

\subsection{In-situ data collection}

RMT surveys are carried out with the aid of the Formation Subsidence Monitoring Tool (FSMT) by Schlumberger. The last variant of this tool consists of a bar of stainless steel equipped with 8 gamma-ray sensors, located in two groups about $10.5 \mathrm{~m}$ apart (Fig. 2).

The main technical problems affecting the record quality are as follows.

- Marker location. The signal intensity decays with the square of the distance. The ideal marker positioning lies 


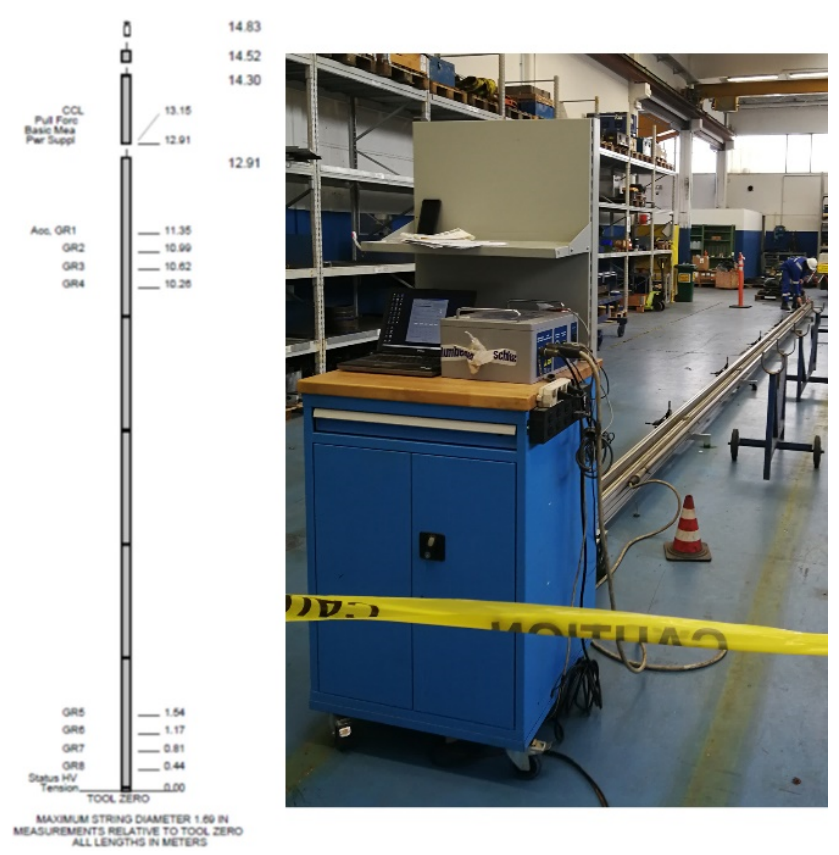

Figure 2. The FSMT logging tool.

between 240 and $420 \mathrm{~mm}$ from the casing. Out of this interval, the signal is either too low or influenced by the casing presence.

- Tool movements. The tool should move at a constant speed from the bottom of the well upward. Any irregular movement adds a noisy error component that can hide the actual signal, especially after several years from the marker installation.

- Reservoir conditions. FSMT is designed in order to limit its deformation up to $175^{\circ} \mathrm{C}$ and 1000 bar. However, monitoring surveys over large depth intervals can be affected by significant temperature and pressure changes.

- Marker spacing. The measurement accuracy progressively decreases when the actual spacing between two consecutive markers moves farther from the separation of the FSMT groups of sensors, i.e., about $10.5 \mathrm{~m}$.

- Time decay. The radioactive marker intensity halves in about 30 years. This means that after a few decades some markers are definitely undetectable.

- Tool calibration. This is a very important stage for ensuring a good measurement quality. If this procedure provides results differing by more than $0.5 \mathrm{~mm}$ before and after the survey, the monitoring campaign should be carried out again.

\subsection{Data interpretation and use}

RMT compaction data are filtered by a statistical analysis and excluded from the records if they do not satisfy strict acceptability tolerances (Mobach and Gussinklo, 2004). Nonetheless, they can present a large statistical dispersion (Baù et al., 2002). The correct interpretation of the collected data is strictly related to their role in the reservoir development. The main motivations for measuring the deep rock compaction are twofold: (i) subsidence monitoring, and (ii) reservoir rock mechanical characterization.

RMT was originally introduced for subsidence monitoring purposes. In the '70s and ' 80 s, it was particularly attractive for monitoring offshore fields or increasing the frequency of measurements with respect to the traditional spirit leveling. Most of these motivations, however, are no longer valid today, because of the development of satellite techniques, such as GPS and InSAR, which allow for an accurate subsidence monitoring with a high frequency in both time and space at a relatively low cost. Nevertheless, the knowledge of deep rock compaction can still be of interest, even if more as a contribution to the calibration of numerical models rather than as a direct subsidence monitoring. The use of RMT compaction measurements for an in-situ rock mechanical characterization is still a matter of great interest. To this aim, however, a number of conditions should be satisfied, in order to avoid misleading interpretations:

- The rock compaction can be directly related to the vertical uniaxial compressibility (Baù et al., 2002) in the hypothesis of oedometric conditions. If other mechanisms are important, such as arch effect, three-dimensional deformation or poro-elastic coupling, RMT data may lead to a compressibility underestimation;

- Even if oedometric conditions are satisfied, the compressibility can be correctly deduced from RMT data by an accurate knowledge of the vertical effective stress acting in the monitored interval. This can be easily obtained from the pore pressure values only under some conditions, such as constant total stress, incompressible grains or absence of significant mechanical heterogeneities;

- RMT data allow for estimating the average compressibility between two points in the $\sigma-\varepsilon$ space, independently of their distance in space or time. Such a value is therefore acceptable if the rock deforms in nearly linear-elastic conditions. Deviations from this hypothesis, which are more likely to occur in long time intervals or with large pressure variations, can lead to inaccurate results;

- A critical issue is the marker location with respect to the actual lithological stratigraphy. The presence of undepleted layers, which could also expand, could give rise 
to inconsistent data, e.g., expansions with a pore pressure decline;

- Possible rate-dependent processes cannot be detected by the RMT analysis and could lead to significant underestimates of the actual rock stiffness.

For these reasons, the rock mechanical characterization derived from marker data has been often the object of debates within the scientific community in the last years.

\section{Discussion and conclusions}

The analysis developed in this work reveals that the RMT methodology for deep compaction monitoring appears to move towards a rapid decline. After the developments in the '80s and '90s, with the RMT implementation in the Netherlands, Brunei, North Sea, Gulf of Mexico and Italy, the oil and gas market has experienced a strong demand contraction for such a technology, which has been abandoned by some major service companies, such as Halliburton and Western Atlas. Currently, deep compaction by RMT is monitored regularly only where land subsidence is felt as a major environmental hazard, such as in some fields of the Northern Adriatic, Italy, and in few chalk reservoirs of the North Sea where compaction can take on extremely significant values, i.e., a minimal percentage of potential market of hydrocarbon reservoirs worldwide. For these reasons, the only service company currently operating with radioactive markers is Schlumberger and no significant technological innovations are under development in this field.

The motivations leading to this situation appear to be only marginally related to the technical difficulties connected with the RMT implementation and the data collection. Most of these difficulties, such as those depending on the irregular FSMT movement along the borehole, the accurate detection of the actual marker position or the reservoir temperature and pressure conditions, have been successfully addressed, and often solved, with the aid of technological advances on the recording tool and the analysis software. Rather, the limited investments on this technology and its abandonment by the major oil companies worldwide appear to be mainly related to the debate on the actual role and importance that these insitu measurements might play in the economic and environmental management of a producing hydrocarbon reservoir. In particular:

a. As a methodology for land subsidence monitoring, like it was originally conceived, the RMT appears to be more expensive, less accurate, less informative and less reliable than other modern techniques used for recording the land motion, such as GPS or InSAR;

b. As in-situ measurements used for the deep rock mechanical characterization, RMT compaction data require several assumptions, which are rarely satisfied in real-world installations. In particular, the most unfavourable situations are those characterized by a pronounced lithological layering and three-dimensional deformation, which are often encountered, for example, in the Northern Adriatic basin (Ferronato et al., 2003). This can limit the RMT relevance for an effective rock mechanical characterization.

Nonetheless, it is hard to conclude that deep compaction measurements are of no interest at all. In the modern computational simulation of land subsidence, they can provide additional pieces of information that contribute to the development of more accurate and reliable predictions. The current trends in the numerical modelling of land subsidence advocate the use of non-deterministic approaches, where the realizations are constrained by the available measurements, and the increase of the number of observations in time and space leads to a progressive uncertainty reduction. For instance, such stochastic approaches can rely on the application of proper data assimilation techniques, which can lead to the development of a novel methodological approach for land subsidence prediction (van Thienen-Visser and Fokker, 2017; Gazzola et al., 2019). In this sense, where already available, RMT measurements can provide a useful contribution to better condition the model outcome (Zoccarato et al., 2018).

It appears unlikely, however, that radioactive markers will be installed for future reservoir developments, especially in basins where RMT is already present and other more convenient land motion monitoring techniques are available. Anyway, the experience acquired over the last 25 years in the Northern Adriatic suggests that, to be effective, FSMT surveys should be scheduled yearly in the initial 5 to 10 years from the installation, when the signal is good and a large pressure variation is usually experienced, and every 3 to 5 years afterward, when pressure changes are smaller and the signal weaker.

Data availability. All the data used for this work are available in the bibliographic references: Baù et al. (2002), Cassiani and Zoccatelli (2000), De Kock et al. (1998), Ferronato et al. (2003, 2004, 2007), Kole (2015), Macini and Mesini (2002), Menghini (1989), Mobach and Gussinklo (1994).

Author contributions. All authors have equally contributed to the bibliographic research. MF and PT wrote the paper.

Competing interests. The authors declare that they have no conflict of interest.

Special issue statement. This article is part of the special issue "TISOLS: the Tenth International Symposium On Land Subsidence - living with subsidence". It is a result of the Tenth International 
Symposium on Land Subsidence, Delft, the Netherlands, 17-21 May 2021.

\section{References}

Baù, D., Ferronato, M., Gambolati, G., and Teatini, P.: Basinscale compressibility of the Northern Adriatic by the radioactive marker technique, Geotechnique, 52, 605-616, 2002.

Cassiani, G. and Zoccatelli, C.: Towards a reconciliation between laboratory and in-situ measurements of slil and rock compressibility, in: Land Subsidence, Proceedings of the 6th International Symposium, vol. 2, 3-15, Padova, Italy, 2000.

De Kock, A. J., Johnson, J., Hagiwara, T., Zea, H. A., and Santa, F.: Gulf of Mexico subsidence monitoring project with a new formation-compaction monitoring tool, SPE Dril. Completion, 13, 223-230, 1998.

De Loos, J. M.: In-situ compaction measurements in Groningen observation wells, Verhandenlingen Kon. Ned. Geol. Mijnbouwk Gen., 28, 79-104, 1973.

Ferronato, M., Gambolati, G., Teatini, P., and Baù, D.: Interpretation of radioactive marker measurements to evaluate compaction in the Northern Adriatic gas fields, SPE Reser. Eval. Eng., 6, 401-411, 2003.

Ferronato, M., Gambolati, G., Teatini, P., and Baù, D.: Radioactive marker measurements in heterogeneous reservoirs: numerical study, Int. J. Geomech., 4, 79-92, 2004.

Ferronato, M., Gambolati, G., Teatini, P., and Janna, C.: Casing influence in reservoir compaction measurement by radioactive markers in the Northern Adriatic, Italy, Int. J. Geomech., 7, 444447, 2007.

Ferronato, M., Castelletto, N., Gambolati, G., Janna, C., and Teatini, P.: II cycle compressibility from satellite measurements, Geotechnique, 63, 479-486, 2013.

Gazzola, L., Ferronato, M., Frigo, M., Janna, C., Teatini, P., Zoccarato, C., Antonelli, M., Corradi, A., Dacome, M. C., and Mantica, S.: Uncertainty quantification and reduction through Data Assimilation approaches for the geomechanical modeling of hydrocarbon reservoirs, in: Proc. 53rd US Rock Mechanics Symposium, 23-26 June 2019, New York City (NY), USA, paper no. $208,2019$.
Hueckel, T., Cassiani, G., Prevost, J. H., and Walters, D. A.: Field derived compressibility of deep sediments of the northern Adriatic, in: Land subsidence: special volume, 25-49, Rotterdam, the Netherlands, 2005.

Kole, P.: In-situ compaction measurements using gamma ray markers, Technical Report no. EP201506209302, NAM, Assen, the Netherlands, 2015.

Macini, P. and Mesini, E.: Measuring reservoir compaction through Radioactive Marker Technique, J. Energy Res. Tech., 124, 269275, 2002.

Macini, P., Mesini, E., Salomoni, V. A., and Schrefler, B. A.: Casing influence while measuring in situ reservoir compaction, J. Pet. Sci. Eng., 50, 40-54, 2006.

Menghini, M. L.: Compaction monitoring in the Ekofisk area chalk fields, J. Pet. Tech., 41, 735-739, 1989.

Mobach, E. and Gussinklo, H. J.: In-situ reservoir compaction monitoring in the Groningen field, in: Proc. EUROCK, 94, 535-547, 1994.

Schmitt, T.: The measurement of the subsidence of geological formations with position sensitive detectors. Application to the oil fields, in: Proceedings of the EU Hydrocarbon Symposium, 2628 November, Edimburgh (Scotland), UK, 1028-1061, 1996.

van Thienen-Visser, K. and Fokker, P.: The future of subsidence modelling: compaction and subsidence due to gas depletion of the Groningen gas field in the Netherlands, the Netherlands, J. Geosci., 96, s105-s116, 2017.

Zoccarato, C., Ferronato, M., and Teatini, P.: Formation compaction vs land subsidence to constrain rock compressibility of hydrocarbon reservoirs, Geomech. Energy Env., 13, 14-24, 2018. 